\title{
The mast cell in early rat adjuvant arthritis
}

\author{
A. GRYFE, ${ }^{*}$ P. M. SANDERS, $\uparrow$ AND D. L. GARDNER + \\ Division of Experimental Pathology, Kennedy Institute of Rheumatology, London
}

Adjuvant arthritis is a prominent feature of the disease which follows 9 to 14 days after normal rats are given a single intradermal injection of a mycobacterial adjuvant mixture. Most accounts of the microscopic changes seen in the limb joints have described the late changes, after the disease is clinically established (Pearson and Wood, 1959; Silverstein and Sokoloff, 1960; Pearson, 1963; Glenn and Gray, 1965; Jones and Ward, 1966).

Studies by Jones and Ward (1963) and by Burstein and Waksman (1964a) analysed the initial lesions but disagreed on the characteristics of the cellular changes. The following study was therefore undertaken to clarify the nature of the earliest cellular responses detectable by light microscopy.

\section{Materials and methods}

96 male albino Wistar rats weighing from 136 to $277 \mathrm{~g}$. were given a single intradermal injection of $0.05 \mathrm{ml}$. of an adjuvant mixture into the left hind footpad. Rats were caged randomly in 24 groups of four and maintained on a standard laboratory pellet diet and water ad lib. The animals, which included untreated, normal controls, were examined daily and weighed, and the carpal and tarsal diameters were measured with calipers. Joint inflammation in each limb was assessed daily and recorded on a 4-point scale (Quagliata, Sanders, and Gardner, 1969).

From the 5th to the 12th days, twelve rats, selected at random, were killed each day. The right hind limb was immediately removed, fixed in formol saline solution, and decalcified. 8 to $10 \mu \mathrm{m}$. paraffin sections were stained with haematoxylin and eosin ( $\mathrm{H}$ and $\mathrm{E}$ ) and examined microscopically for synovitis, myositis, periostitis, periarticular cellulitis, periosteal hyperplasia, and new bone formation. The numbers of mast cells, lymphocytes, histiocytes, and polymorphs infiltrating the tissues, the degree of soft tissue oedema, the amount of inflammatory exudate in joint spaces, and the numbers of cells and quantity of fibrin in the joint space exudate were assessed. The number of intact and of degranulated mast cells in representative areas of the synovial and periarticular tissues was also determined.

\section{Results}

Six of the twelve rats killed on the 10th day, ten of twelve on the 11th day, and each of twelve on the 12th day displayed clinical evidence of arthritis in the non-injected right hind limb at the time of death (Fig. 1).

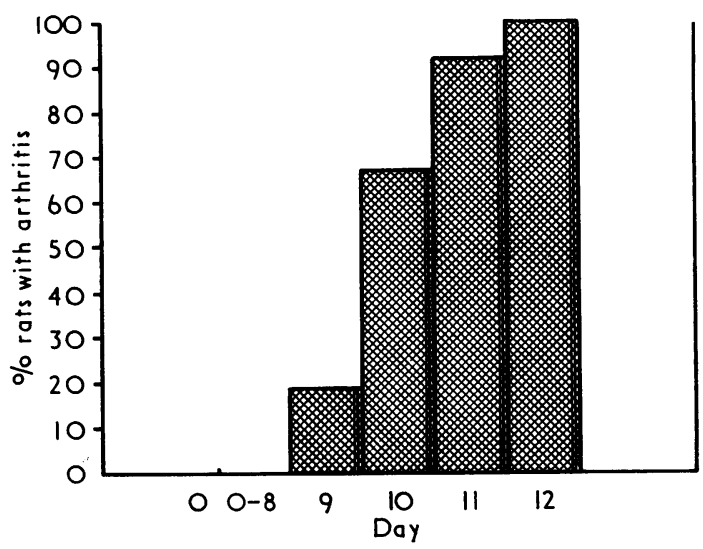

FIG. 1 Time of onset of clinical signs of adjuvant arthritis after injection of mycobacterial adjuvant at Day 0.

Histological abnormalities were detected in or around all affected joints. Inflammation appeared to arise in the loose connective tissue of the joint and tendon sheath synovium, and in the periarticular loose connective tissues (Figs 2 and 3). The reaction spread directly to adjacent skeletal muscle and periosteum (Figs 4 and 5). The earliest microscopic change recognized was oedema (Fig. 6) observed in two rats at Day 5 and in three, four, and six rats at Days 6, 7, and 8 respectively.

\section{MAST CELLS}

These were the first to appear in abnormal numbers (Figs 7 and 8); they were numerous in perisynovial and periarticular tissues of normal rats but many more than normal were evident in the non-injected

\footnotetext{
* Pathologist, Hamilton Health Association, Hamilton, Canada

+ Junior Research Fellow, Medical Research Council

¥ Director, Sir Edward Lewis Lecturer, and Head of Division of Experimental Pathology, Kennedy Institute

Requests for reprints should be addressed to D. L. G., Kennedy Institute, Bute Gardens, London, W.6.
} 


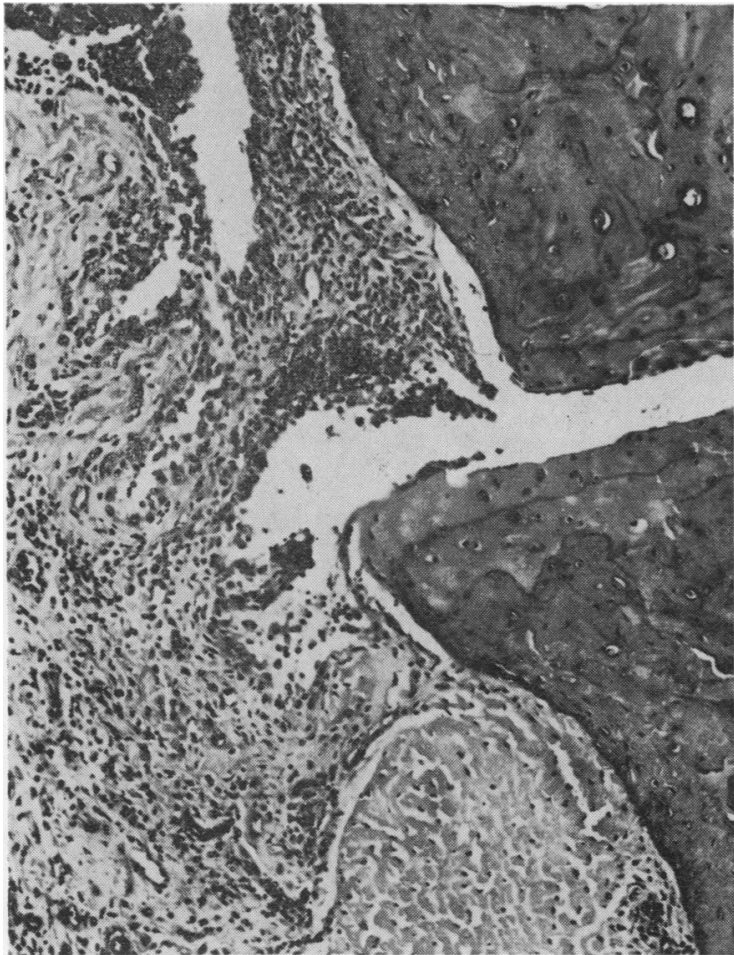

FIG. 2 Early histological evidence of synovitis in right hind limb 10 days after injection of adjuvant into left foot pad. Haematoxylin and eosin. $\times 100$.

feet of rats killed 5 days after the injection of adjuvant. The numbers continued to increase until the 6th day and then declined, at first rapidly and then more gradually. No mast cells were recognized among the synovial cell layers of normal rat limbs, but in a small proportion of treated rats on each day after the 4th, occasional mast cells appeared in this site. No mast cells were seen lying free in joint spaces, whether or not an inflammatory exudate was present. Mast cells devoid of cytoplasmic granules were first identified on Day 11; by Day 12 very few cells with granules were seen.

\section{LYMPHOCYTES}

Increased numbers (Fig. 6) appeared constantly on Day 10. A few perivascular lymphocytes were noted on Day 8 , but by the 10th day, eight rats exhibited these cells in significantly increased numbers. However, only six of these animals had arthritis. By the 11th day, eleven rats displayed lymphocytes in moderate-to-large numbers in synovial and periarticular tissues; ten of the twelve rats in this group showed clinical disease. All rats killed on Day 12 demonstrated lymphocytic infiltration, first as clusters around blood vessels and then diffusely throughout the tissues.

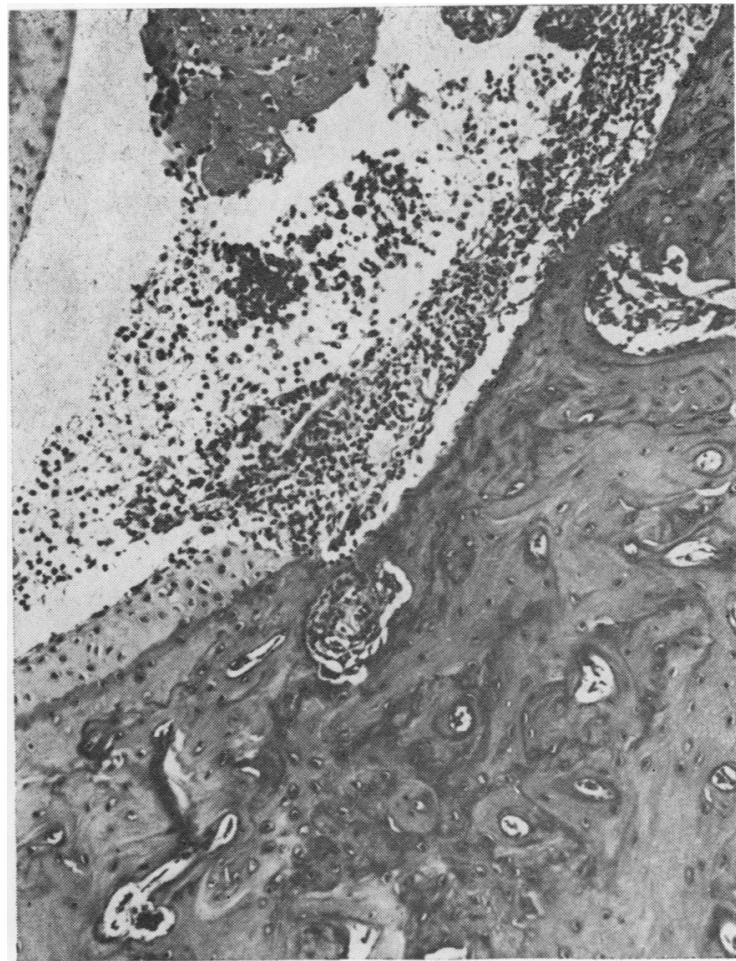

FIG. 3 Marginal destruction of articular cartilage by inflammatory cell exudate 11 days after injection of adjuvant into foot pad of opposite foot. $H$ and $E . \times 100$.

\section{HISTIOCYTES}

These appeared in increased numbers later (Fig. 6). They were observed in only two animals on Day 10 but in eight on Day 11, when their numbers were generally lower thah those of the lymphocytes. On Day 12 the number of lymphocytes often exceeded that of histiocytes.

\section{POLYMOR PHS}

With one exception none was seen until the 10th day when they could be detected in six animals (Figs 6 and 9). At first the number was low, and almost all were confined to vascular lumina. Thereafter, the cells rapidly increased in number but still remained largely within the blood vessels. Not until they were numerous did these cells appear in the surrounding tissue; at this time they could often be seen traversing blood vessel walls. On Day 11, when eleven of the twelve rats showed synovial polymorph infiltration, many of these cells were still intravascular or perivascular. Although the number of polymorphs greatly increased on the 11 th and 12th days, they were usually fewer than the lymphocytes and always scarcer than the combined lymphocyte and histiocyte population. When degranulated mast cells appeared, polymorphs were already present in 


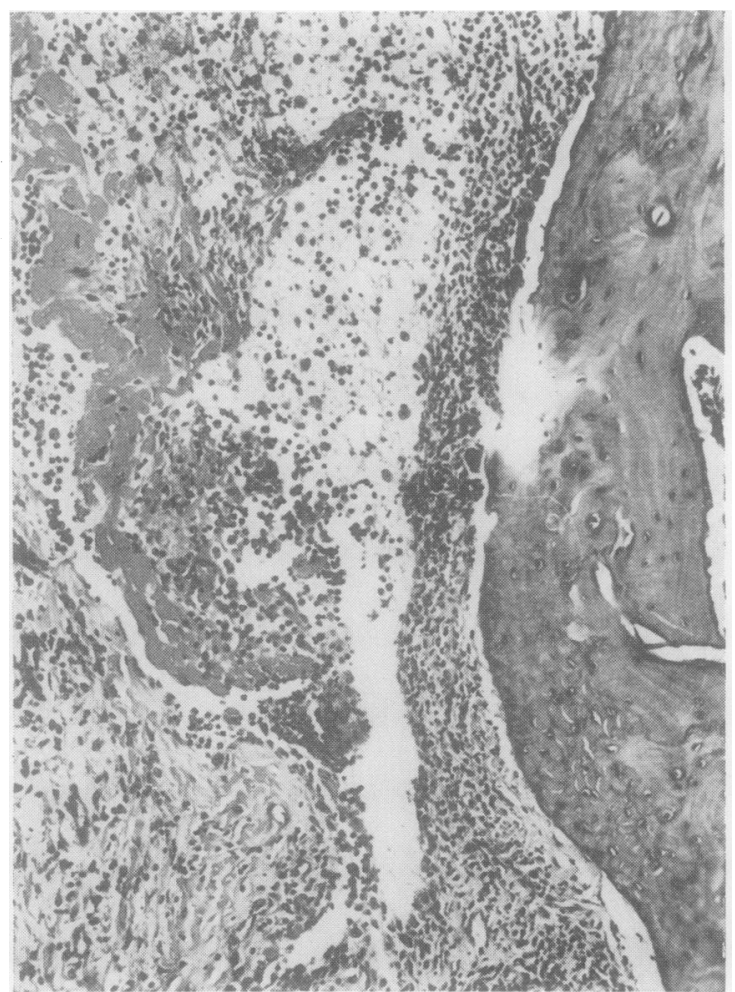

FIG. 4 Aggregates of inflammatory cells in periosteal and para-articular connective tissues 12 days after injection of adjuvant into opposite hind foot. Note fibrin masses (dark grey) in joint space. $H$ and $E . \times 100$.

the tissues. However, when polymorphs were still confined to blood vessels, mast cells invariably possessed intact granules.

The joint exudate consisted mainly of polymorphs enmeshed in fibrin (Fig. 4). Mononuclear cells were either not seen or were sparse and consisted mainly of histiocytes. Lymphocytes were scarce. The few lymphocytes and relatively numerous polymorphs did not reflect the preponderance of lymphocytes in the tissues. The earliest joint exudate appeared in one rat, at Day 10, which had developed clinical arthritis at Day 9. Of the eleven rats with histological evidence of synovitis on Day 11, four had inflammatory exudate in the joint spaces and in three the exudate was present in at least moderate amount. Three of these four rats had arthritis in non-injected limbs on Day 9 and the 4th developed arthritis on Day 10.

No exudate was seen in the joint space in the absence of established histological synovitis, although in one rat killed on Day 12 a scanty exudate appeared when the degree of synovitis was only mild and the number of polymorphs in the synovium small with the majority still intravascular. When fibrin was seen it was always accompanied by polymorphs.

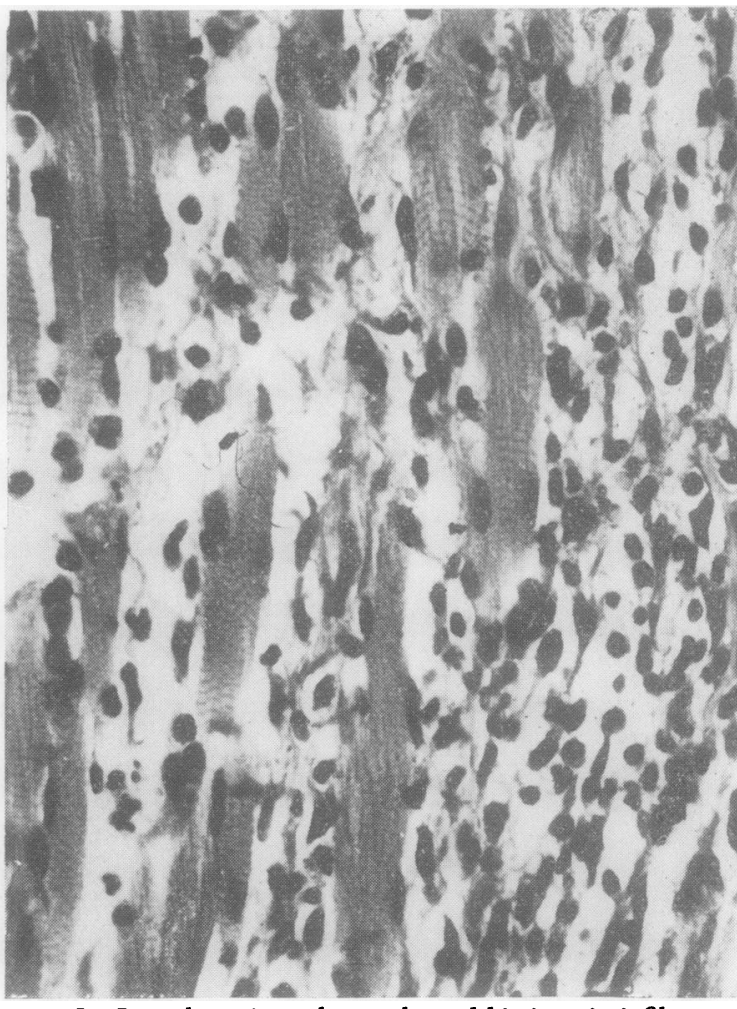

FIG. 5 Lymphocytic, polymorph, and histiocytic infiltrate of skeletal muscle adjoining inflamed joint 12 days after injecting mycobacterial adjuvant into the opposite foot. $H$ and $E . \times 250$.

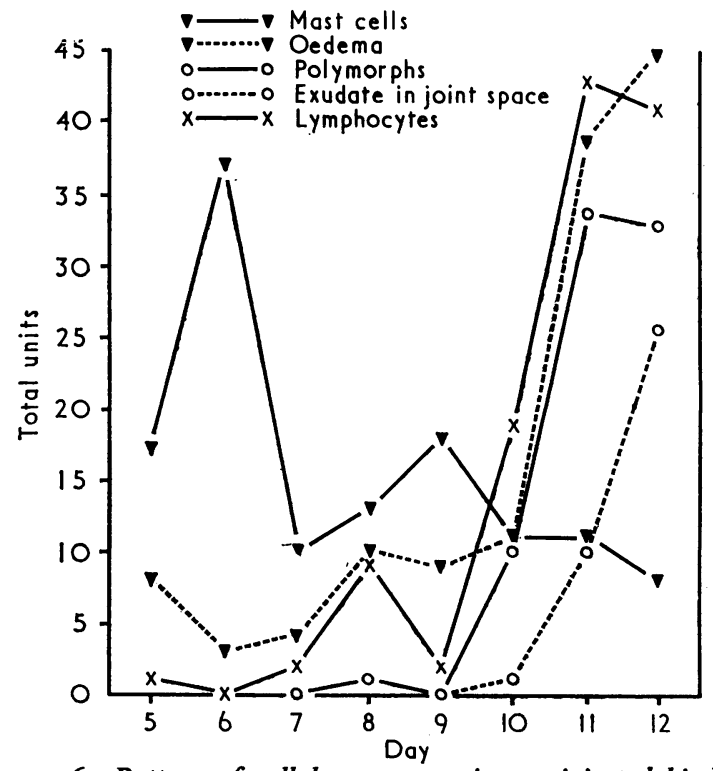

FIG. 6 Pattern of cellular response in non-injected hind foot in adjuvant arthritis. Note early peak of mast cell response followed by early regression, and later peaks of oedema, and of polymorph and lymphocyte infiltration. Two animals, however, displayed oedema at Day 5. 


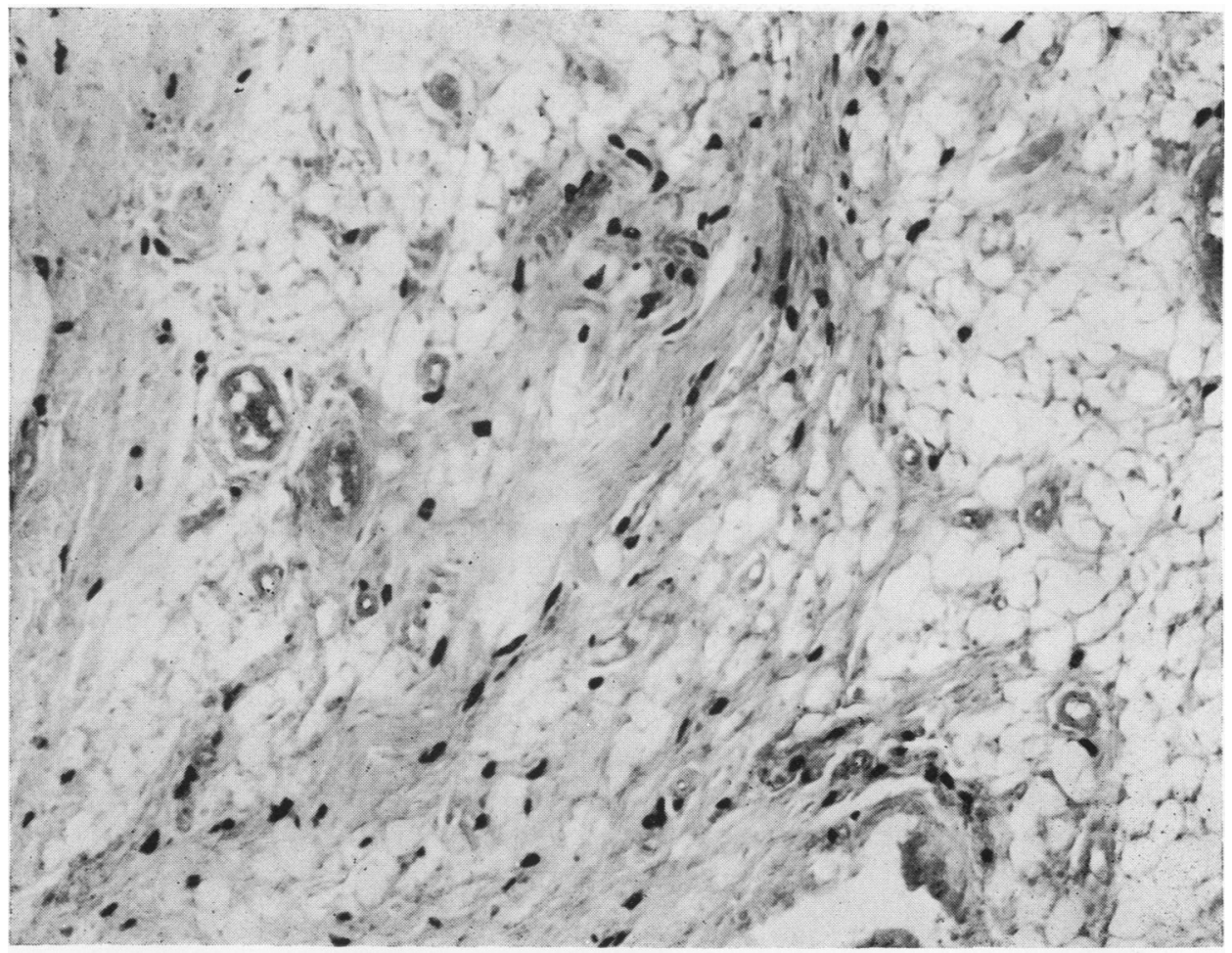

FIG. 7 Distribution of mast cells in right hind foot connective tissue 6 days after injection of mycobacterial adjuvant into the opposite foot. Mast cells stand out as small black bodies. Toluidine blue. $\times 150$.

\section{Discussion}

It is shown that mast cells are the first cells to appear in abnormal numbers in the inflamed tissues in rat adjuvant arthritis.

Mast cells are normally large, numerous, and conspicuous in many rat tissues, including the synovium and the periarticular structures (Rosate, 1959; Selye, 1965). They can be recognized with ease in sections stained with haematoxylin and eosin and have prominent metachromatic cytoplasmic granules. Identification of mast cells is more difficult after the granules have been lost. Under these conditions they are recognized as swollen cells with a central nucleus and basophilic cytoplasm in which a few peripheral granules are occasionally seen (Parratt and West, 1957).

In adjuvant arthritis, a sequence of changes is noted in the mast cell population. There are increased numbers, apparent infiltration by mast cells of the synovial cell layers lining joint spaces, and degranulation. The first two changes begin at approximately the same time. More than the normal proportion of mast cells is seen by the 5th day, but this number markedly and suddenly increases on Day 6 and then decreases, at first sharply and then more gradually. The literature on rat adjuvant arthritis contains no previous reference to this cell population.

Mast cells are believed to be the major source of histamine in rats (Keller, 1966). Keller has discussed the release of histamine by degranulation and sometimes by cytolysis of mast cells. In the present study, both mechanisms could explain the fall in the numbers of mast cells after the 5th day, the former resulting in mast cells which are more difficult than normal to identify, the latter decreasing the actual numbers. Why mast cells should contribute to the inflammatory reaction in adjuvant disease is more difficult to resolve. According to Sheldon and Bauer (1960), tissue mast cells initiate acute inflammation at many sites of injury. These cells, the histamine released from them, and possibly other products such as heparin and 5-hydroxytryptamine, are considered to take part in anaphylactic immune reactions (Keller, 1966). However, adjuvant disease is believed by most authorities to be due to hypersensitivity of the delayed type (Waksman, Pearson, and Sharp, 1960; Sharp, Waksman, Pearson, and Madoff, 1961; Pearson, 1963; Waksman and Wennersten, 1963; Pearson and Wood, 1964). It remains possible that mast cells contribute to the first part of a biphasic inflammatory reaction in adjuvant disease. 


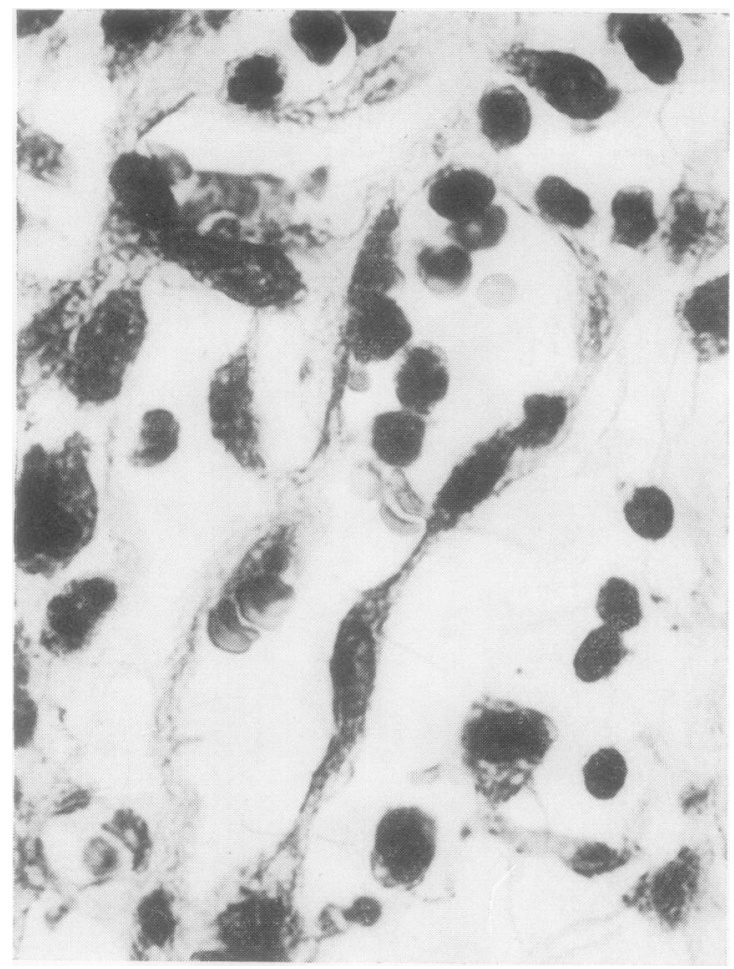

FIG. 8 Venule in inflamed connective tissue in early rat adjuvant arthritis. Mast cells are seen as large cells with ovoid or round nuclei (top right and lower right).

$H$ and $E . \times 540$.
Degranulation of mast cells in adjuvant arthritis is not observed until polymorphs have crossed $\frac{}{\circ}$. vessel walls and gained access to the tissues. This confirms the findings of Janoff and Schaefer (1967) who demonstrated that polypeptides from the $\overrightarrow{0}$ lysosomes of polymorphs effectively degranulated $\frac{c}{0}$ mast cells. It also suggests that the increase in $\frac{\bar{m}}{\bar{m}}$ vascular permeability, with oedema, found as the $\mathbb{D}$ earliest histological feature of adjuvant arthritis, is not necessarily dependent upon the release of mast ${ }^{\circ}$ cell histamine.

In normal human synovium, mast cells do not $\overrightarrow{\vec{\omega}}$ occur in the layers of synoviocytes (Barnett, Davies, and MacConaill, 1961); nor were they seen in our $\frac{2}{2}$ control animals. In the injected rats, very occasional $\omega$ mast cells appear to have gained access to the layers of synovial cells lining joint cavities, but none was is observed within the joint spaces. This is not the case 0 with other cells, particularly polymorphs, which constitute the predominant cell population in joint $\vec{c}$ exudates. Intra-articular histiocytes, morphologically similar to and possibly arising from the synovial cell lining, are much fewer in number and $₹$ lymphocytes are uncommon in joint exudates. A $\overrightarrow{0}$ preponderance of mononuclear cells in the synovium $\unlhd$ and of polymorphs in the synovial fluids, of course, a common finding in other forms of animal and of human arthritis (Gardner, 1965; 1969). The histological features of the joint effusion of adjuvant arthritis are those of a nonspecific acute inflam- $\frac{\odot}{\Phi}$ matory exudate. Polymorphs appear later than

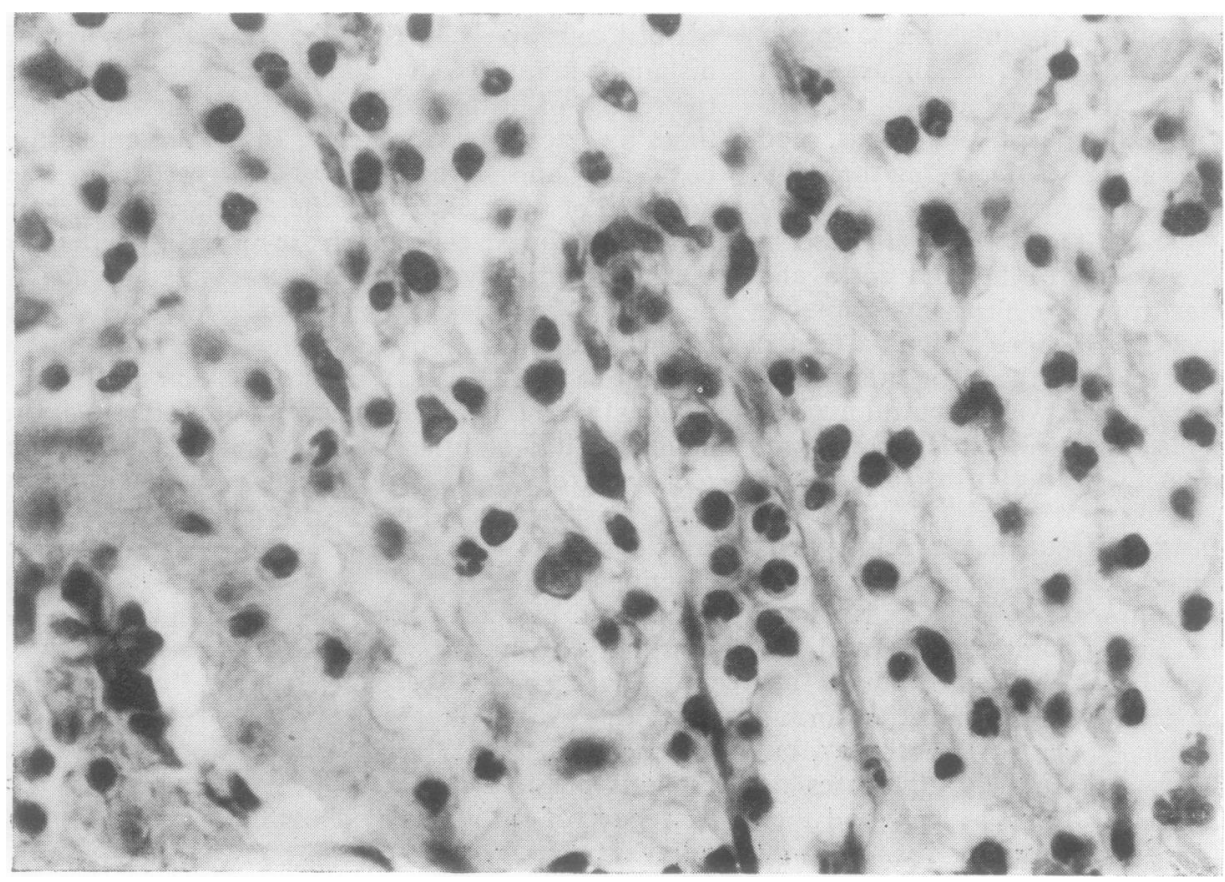

FIG. 9 Polymorphs in early 윽 adjuvant arthri- $D$ tis, accumulating 을 locally in venule $\mathrm{N}$ (centre) and mi- O grating into ad- $\mathrm{O}$ jacent connective N tissue. $H$ and $E$. $\times 320$. 
lymphocytes in this inflammatory reaction and they accumulate within and engorge blood vessels before gaining access to the tissues. Lymphocytes do not accumulate within vessels in the inflammation of adjuvant arthritis; they are first seen in a perivascular location from which they migrate to the tissue spaces. When polymorphs migrate, they do not appear to delay in a perivascular location but quickly enter the tissue spaces.

It is confirmed that the inflammation of adjuvant disease begins in synovial and periarticular connective tissue and that it spreads directly to involve skeletal muscle and periosteum, the sequence observed by Jones and Ward (1963). Oedema, an early sign of inflammation, can be identified at the site of the developing inflammatory reaction before cellular infiltration (Movat, 1966), a sequence noted in the present study.

The precise mechanism of the inflammation of adjuvant arthritis has not yet been defined. Acid-fast bacilli have been shown within adjuvant droplets in primary and secondary lesions (Akamatsu, Nishizawa, Watanabe, and Kumagai, 1966) and radioactivity has been demonstrated around joints after the intradermal injection of labelled adjuvant (Jones and Ward, 1964), suggesting that components of adjuvant are conveyed to, and may localize in, synovial tissue. The dissemination of adjuvant or of the products of adjuvant alone could incite an inflammatory reaction, a view supported by Lack (1968). Thus, Newbould (1964) showed that removal of lymph nodes draining an injection site within 5 days of the administration of adjuvant prevented the development of secondary lesions, while lymphadenectomy on or after the 7th day did not. This suggested that, if adjuvant dissemination were necessary for initiation of the inflammatory process, this dissemination would probably occur by the 5th or 6th day. That this time is critical was also confirmed by Quagliata and others $(1968 ; 1969)$ who demonstrated that either Rubidomycin or an antilymphocytic serum would prevent adjuvant disease only if given before the 5th day.

The theory that adjuvant disease is due to delayed hypersensitivity is persuasive (Waksman and others, 1960; Sharp and others, 1961; Pearson, 1963; Waksman and Wennersten, 1963; Pearson and
Wood, 1964). The appearance of lymphocytes before polymorphs supports this view and that of Burstien and Waksman (1964a). These authors point out that the discrepancies between their findings and those of Jones and Ward (1963) may arise first from the latter's failure to examine joint sections 1 to 2 days before the onset of clinical arthritis, and secondly from the differences in strains of rat, in adjuvant mixtures, and in routes of inoculation employed. With autoradiographic methods, Burstein and Waksman (1964b) have shown that the lymphocytes which appear in the tissues are haematogenous in origin and that a significant proportion of histiocytes are derived from these lymphocytes. This appears to explain why histiocytes appear later than lymphocytes. The combined lymphocytes and histiocytes usually outnumber the polymorphs, even in wellestablished lesions.

\section{Summary}

A survey has been made of the cell populations of the joints and periarticular tissues of rats during the phase of onset of experimental adjuvant arthritis. The investigation began before clinical evidence of arthritis was identifiable and extended from the 5th to the 12th day after the injection of adjuvant.

The phenomena of inflammation were first recognized in synovial and perisynovial zones; they then spread to adjacent tissue. Mast cells were the first to appear in excess, although oedema was the earliest disturbance suspected microscopically. Aggregates of lymphocytes were seen before polymorphs accumulated in extravascular planes, and were first recognized as perivascular clusters. With the spread of polymorphs into perisynovial tissues, histiocytes infiltrated these zones and mast cells became degranulated. An inflammatory joint exudate appeared only after synovitis was established; polymorphs predominated in these effusions and mononuclear cells in the tissues.

This work would not have been possible without the generous support of the Arthritis and Rheumatism Council for Research.

We are grateful to Mr. George Munroe for expert technical assistance and to Mrs. Mei Ling Foo for help with the preparation of the manuscript.

\section{References}

Akamatsu, Y., Nishizawa, H., Watanabe, S., and Kumagai, A. (1966) Acta path. jap., 16, 131 (Adjuvant-induced polyarthritis in rats-Its histogenesis).

Barnett, C. H., Davies, D. V., and MacConaill, M. A. (1961) 'Synovial Joints: Their Structure and Mechanics', p. 28. Longmans, London.

Burstein, N. A., And Waksman, B. H. (1964a) Yale J. Biol. Med., 37, 177 (The pathogenesis of adjuvant disease in the rat. $\mathbf{I}$. A histologic study of early lesions in the joints and skin).

(1964b) Ibid., 37, 195 (The pathogenesis of adjuvant disease in the rat. II. A radioautographic study of early lesions with the use of $\mathbf{H}^{3}$-thymidine). 
Gardner, D. L. (1965) 'Pathology of the Connective Tissues Diseases', Arnold, London.

(1969) 'Pathology of the Rheumatic Diseases', in 'Textbook of the Rheumatic Diseases', ed. W. S. C. Copeman, 4th ed., p. 87. Livingstone, Edinburgh and London.

GLENN, E. M., AND GRAY, J. (1965) Amer. J. vet. Res., 26, 1180 (Adjuvant-induced polyarthritis in rats: Biologic and histologic background).

JANOFF, A., AND SCHAEFER, S. (1967) Nature (Lond.), 213, 144 (Mediators of acute inflammation in leucocyte lysosomes).

JoNEs, R. S., AND WARD, J. R. (1963) Arthr. and Rheum., 6, 23 (Studies on adjuvant-induced polyarthritis in rats. II. Histogenesis of joint and visceral lesions).

- (1964) 'Proceedings of the IVth International Symposium on Reticulo-endothelial systems, Otsukyoto, Japan', p. 298 (Tissue distribution of radioisotopically labelled components of adjuvant). (1966) 'Adjuvant-induced polyarthritis in rats', in "Methods and Achievements in Experimental Pathology", vol. 1, p. 607, ed. E. Bajusz and G. Jasmin. Karger, Basel and New York.

KelLer, R. (1966) 'Tissue Mast Cells in Immune Reactions'. Elsevier, New York.

LACK, C. H. (1968) Med. Clin. N. Amer., 52, 667 (Experimental models of rheumatoid arthritis).

MovAT, H. Z. (1966) 'The vascular changes in acute normergic (non-allergic) and allergic inflammation', in "Methods and Achievements in Experimental Pathology", vol. 1, p. 245, ed. E. Bajusz and G. Jasmin. Karger, Basel and New York.

NewBould, B. B. (1964) Ann. rheum. Dis., 23, 392 (Role of lymph nodes in adjuvant-induced arthritis in rats).

PARratt, J. R., AND WeST, G. B. (1957) J. Physiol. (Lond.), 137, 179 (Release of 5-hydroxytryptamine and histamine from tissues of the rat).

Prarson, C. M. (1963) J. chron. Dis., 16, 863 (Experimental joint disease. Observations on adjuvant-induced arthritis).

- AND WOOD, F. D. (1959) Arthr. and Rheum., 2, 440 (Studies of polyarthritis and other lesions induced in rats by injection of mycobacterial adjuvant. I. General clinical and pathologic characteristics and some modifying factors).

- - (1964) J. exp. Med., 120, 547 (Passive transfer of adjuvant arthritis by lymph node or spleen cells).

Quagliata, F., SANDERS, P. M., AND Gardner, D. L. (1968) 'Communication to the Pathological Society of Great Britain and Northern Ireland, Bristol, July 1968' (Abstr. 22) (Suppression and transfer of adjuvant disease in rats).

__ _ - (1969) Ann. rheum. Dis., 28, 163 (Suppression of adjuvant arthritis by a new cytotoxic compound, Rubidomycin).

Rosate, A. (1959) Biol. lat. (Milano), 12, 451 (Mastocytes (mast cells) of the synovial stratum in normal and experimentally immobilized diarthroses) (Italian).

SalYz, H. (1965) 'The Mast Cells'. Butterworth, Washington, D.C.

Sharp, J. T., Waksman, B. H., Pearson, C. M., and Madofr, S. (1961) Arthr. and Rheum., 4, 169 (Studies of polyarthritis and other lesions induced in rats by injection of mycobacterial adjuvant. IV. Examination of tissues and fluids for infectious agents).

Shreidon, W. H., AND BAUER, H. (1960) J. exp. Med., 112, 1069 (Tissue mast cells and acute inflammation in experimental cutaneous mucormycosis of normal, 48/80-treated, and diabetic rats).

Silverstein, E., AND SOKOLOFF, L. (1960) Arthr. and Rheum., 3, 485 (Periarthritis produced in rats with Freund's adjuvant).

Warsman, B. H., Pearson, C. M., ANd Sharp, J. T. (1960) J. Immunol., 85, 403 (Studies of polyarthritis and other lesions induced in rats by injection of mycobacterial adjuvant. II. Evidence that the disease is a disseminated immunologic response to exogenous antigen). AND Wenneresten, C. (1963) Int. Arch. Allergy, 23, 129 (Passive transfer of adjuvant arthritis in rats with living lymphoid cells of sensitized donors). 